\title{
Lisboa em Cardoso Pires e Saramago: imagens de retorno
}

\author{
Maria Luiza Scher Pereira \\ Universidade Federal de Juir de Fora
}

RESUMO: TANTO JOSÉ CARDOSO PIRES COMO JOSÉ SARAMAGO FIZERAM DE LISBOA MOTIVO DE VISITAÇÃO E DE TEXTUALIZAÇÃO. PARA CARDOSO PIRES, UMA CIDADE DE NAVEGAR, UMA CIDADE-NAVE; PARA SARAMAGO, UMA CIDADE AUTOFÁGICA, QUE NÃO GOSTA DE RUÍNAS. PARA AMBOS, INTELECTUAIS EM TRÂNSITO, A CIDADE-TEXTO, EM QUE IMAGENS DE RETORNO REPRESENTAM A ARTICULAÇÃO, CONFLITUOSA MAS FECUNDA, ENTRE OS MITOS DE ESPAÇO E TEMPO E A SUBJETIVIDADE QUE OS TRANSFORMAM EM MOTIVOS DE LEITURA E DE ESCRITA.

RESUMEN: TANTO JOSÉ CARDOSO PIRES COMO JOSÉ SARAMAGO HAN HECHO DE LISBOA MOTIVO DE VISITACIÓN Y DE TEXTUALIZACIÓN. PARA CARDOSO PIRES, UMA CIUDAD DE NAVEGAR, UMA CIUDAD-NAVE; PARA SARAMAGO, UMA CIUDAD AUTOFÁGICA A LA QUE NO LE GUSTAN LAS RUINAS. PARA AMBOS, INTELECTUALES EN TRÁNSITO, LA CIUDAD-TEXTO, EN QUE IMÁGENES DE RETORNO REPRESENTAN LA ARTICULACIÓN CONFLICTUOSA MÁS FECUNDA ENTRE LOS MITOS DE ESPACIO Y TIEMPO Y LA SUBJECTIVIDAD QUE LOS TRANSFORMAM EN MOTIVOS DE LECTURA Y DE ESCRITA.

PALAVRAS-CHAVE: CARDOSO PIRES, SARAMAGO, LISBOA, INTELECTUAIS EM TRÂNSITO, MEMÓRIA.

PALABRAS-CLAVE: CARDOSO PIRES, SARAMAGO, LISBOA, INTELECTUALES EN TRÁNSITO, MEMÓRIA. 
retorno, além de dar o mote para essa reflexão, também me fez pensar na volta permanente que nós, professores de literatura portuguesa, fazemos a determinadas questões cada vez que nos debruçamos sobre esse corpus para preparar nossos cursos e aulas, e avançar com nossas pesquisas.

Leitores especializados que somos, contudo não podemos, e nem queremos, resistir ao gosto particular, à preferência pessoal, às escolhas subjetivas. $\mathrm{O}$ fato é que, por motivos não completamente revelados e não exclusivamente intelectuais, alguns textos e alguns autores seguem sendo nossos mais recorrentes objetos de desafio intelectual, de sedução estética, e, principalmente talvez, de prazerosa recepção. Por isso, sempre a eles retornamos.

É o caso de Cardoso Pires para mim. Sempre voltei ao texto de Cardoso Pires, principalmente aos romances, mas também aos contos, aos textos críticos, e mais recentemente ao intrigante De profundis, valsa lenta. Até agora, não tinha, no entanto, me dedicado a esse Lisboa, livro de bordo a não ser como a leitora interessada que sempre fui de sua obra.

A pesquisa acadêmica que venho desenvolvendo - "Intelectuais em trânsito: arquivos do exilio", em que focalizo mais especificamente os olhares cruzados que intelectuais e escritores portugueses e brasileiros lançam sobre Portugal e Brasil, sobre a Europa e a América Latina no contexto do modernismo e da contemporaneidade - acabaria mais cedo ou mais tarde motivando a extensão da leitura de fruição desse livro para o exercício de reflexão crítica, já que Lisboa livro de bordo (1997) é resultado de uma forma de trânsito, o do intelectual que retorna à casa (no caso, sua própria cidade), que ele percorre, apesar de conhecê-la muito, com um olhar necessariamente deslocado.

A prática comparatista que orienta a pesquisa me fez inclinar para o cotejamento do texto com outro, seu contemporâneo, igualmente construído sob a metáfora da viagem: o Viagem a Portugal (1981), de José Saramago. Como a viagem construída por Saramago é mais extensa, pratiquei recortes e incisões até o viajante chegar a Lisboa, pois me interessava como os dois olhares sobre o mesmo objeto se representam em discursos e perspectivas literárias que são bastante específicas, embora nasçam no mesmo espaço e em condições semelhantes de enunciação.

Nos dois livros, temos a mesma perspectiva em deslocamento, própria do intelectual em trânsito e própria do trânsito do intelectual pelo campo do discurso da literatura nesse momento específico do fim do século XX. Para 
Cardoso Pires, Lisboa é a cidade de navegar, ou "cidade-nave". Nesse movimento de navegação, o escritor se distancia da cidade conhecida, familiar, e retorna a ela, para tentar apreendê-la com o olhar deslocado, num processo de conhecimento do novo, só possível com a percepção subjetivada de Lisboa: "[...] é uma cidade em geometria esquiva, colinas, requebros, ondulações, reflexos dum rio a tons incertos, conforme os dias e conforme as marés, um corpo para soletrar sem pressas".

Também José Saramago já a partir do título Viagem a Portugal adota a posição de quem, tendo se afastado, está de volta à casa. Por que o autor, sendo português, e estando nele, viajaria $a$ seu país, se não fosse para o rever com um olhar diferente, um olhar necessariamente alterado pela tomada de distância?

Ambos, cada um a seu modo, parecem responder àquele "imperativo moral" de se colocar fora de casa, de que fala Adorno no seu livro Mínima Moralia. A experiência do exílio, apesar de dilacerante, guardaria uma paradoxal positividade, pois é condição para se obter um olhar deslocado, resultante da alteração de ótica que o afastamento possibilita.

Cardoso Pires e Saramago nesses livros de viagem parecem também registrar as experiências de afastamentos e de retornos inevitáveis e necessários ao intelectual, naquele processo de relação complexa com a tradição, que o escritor e crítico argentino Ricardo Piglia chama de "ex-tradição".

O sentido geral do termo "extradição" é o da deportação do estrangeiro, isto é, ele, estando fora, é forçado a voltar para seu país. Jogando com a separação do prefixo, Piglia (1991) reinventa o termo e amplia seu sentido para propor a idéia de que um escritor sempre trabalha com a ex-tradição: num sentido, trabalha com os rastros de uma tradição perdida, quase olvidada; em outro, com a obrigação de cruzar a fronteira de volta, levado ou trazido a ela, sempre pela força: "obligado siempre a recordar una tradición perdida, forzado a cruzar la frontera”.

O intelectual ou o escritor por formação asila-se na alta-cultura, na "cidade letrada", mas como não pode jamais esquecer completamente a sua tradição, volta sempre à casa. De volta a ela, não pode mais alienar-se da sua formação

${ }^{1}$ PIRES, José Cardoso. Lisboa Livro de bordo. Vožes, olhares, memorações. 4 ed., Lisboa: Dom Quixote. 1998. p. 38-39. 
letrada, e é com ela que transita no seu próprio espaço para re-conhecê-lo, sendo para sempre então um ser deslocado, um estrangeiro nos dois lugares. Por isso, segundo a idéia de Piglia, "la figura de la extradición es la patria del escritor" e lhe dá "la conciencia de estar siempre en un lugar desplazado e inactual."

Minha hipótese de leitura desses livros de viagem de Cardoso Pires e de José Saramago é a de que ambos escrevem sobre o retorno que expõe a cisão causada pelo duplo pertencimento: ao acervo da formação culta, autores, referências, textos; e à memória particular, feita de resíduos e traços, reencontrada na experiência pessoal da volta à casa.

Tomemos inicialmente o livro de Cardoso Pires. Seu Lisboa, livro de bordo, é um passeio de "viajante errante na paixão" pela cidade, mas mediado pelo passeio pela cidade das letras, lisboetas ou não, tornadas por escolha do escritor suas contemporâneas.

A cidade é vista pelo seu olhar criativo, mas também pelo olhar criativo de seus pares: escritores como O’Neill, Lobo Antunes, Pessoa, Almada Negreiros, mas também Bocage, Camões, Damião de Góis; e pintores e artistas plásticos: Abel Manta, Júlio Pomar, também Vieira da Silva, entre muitos outros.

O passeio e o livro terminam com o escritor sentado num café do Terreiro do Paço e, como tem "a cidade pelas costas", a "última vista" da Finis Terrae inclui tanto o bailado das gaivotas do Tejo como os textos de que vai se recordando, e com os quase dialoga: Tirso de Molina, Fielding, Beckford, Sade, Tabbuchi. Nas suas palavras:

Um dia pode acontecer que sentados como agora sobre o rio, a tentemos ler pela voz dos outros e então nos sentiremos mais errantes, mas incertos. (...) Vozes, tudo vozes. Olhares. Memorações. Quando por fim fechamos a página onde líamos a cidade, descobrimos que a vidraça do café está toldada por uma dança de gaivotas em turbilhão... (e) reconhecemo-nos ainda mais ancorados à cidade que nos viu partir. ${ }^{3}$

\footnotetext{
2 PIGLIA, Ricardo. "Memoria y tradición". Anais do $2^{\circ}$ Congresso da Abralic. Vol. 1. Belo Horizonte: UFMG, 1991. p. 61.

${ }^{3}$ PIRES, José Cardoso. Lisboa Livro de bordo. Vožes, olhares, memorações. 4 ed., Lisboa: Dom Quixote. 1998. p. 117.
} 
A navegação de Cardoso Pires então se orienta por dois movimentos: um que percorre os textos literários e os trabalhos artísticos dos autores de sua eleição; o outro caminho é o da experiência do movimento da cidade, e seus aspectos menos turísticos, como os bares só freqüentados pelos moradores locais, os recantos da Vila Berta, detalhes que podem passar despercebidos, como os desenhos nas calçadas de pedra; ou personagens do cotidiano como os anônimos "velhos de jardim".

No entanto, se predomina o movimento do literário, próprio do intelectual, há sempre um tom de irreverência irônica, própria de Cardoso Pires, que impede a solenidade e dimensiona de modo não reverente o tratamento desses textos literários e dessas obras artísticas.

Além disso, a literatura e a alta cultura, que fazem parte do acervo particular do intelectual, e, portanto, não podem ser negadas, convivem com as letras dos fados vadios, com alegorias da tradição cultural, como os corvos de São Vicente, com anedotas políticas e histórias populares, e com a fruição de outra Lisboa, a que não faz parte do "slide oficial":

Enfim, esquecendo o slide oficial, as setas do turismo, alfamas, miradouros, fados-fadários, pode-se ir dar - outro supor - ao Alto da Graça. Que é um sítio à balda, havemos de concordar; um desabono para a vista, à parte aquela varanda de jardim que dá para uma das Lisboas até ao Tejo de que falam os roteiros. ${ }^{4}$

A Lisboa do escritor é diferente da do turista, porque ele nesse momento vivencia o retorno do intelectual ao mundo, à cidade, e sem a segurança da ficção. E isso não se dá sem dor:

[...] um mundo privado como o teu, ninguém aprende a vivê-lo. Eu, melhor ou pior, vou tentando. Para chegar a esse entendimento, já recapitulei infâncias de bairro, já revisitei lugares; já te disse e contradisse, Lisboa, e sempre em amor sofrido. ${ }^{5}$

${ }^{4}$ PIRES, José Cardoso. Lisboa Livro de bordo. Vozes, olhares, memorações. 4 ed., Lisboa: Dom Quixote. 1998. p. 86.

${ }^{5}$ Id. Ibid. p. 13. 
Talvez para exorcizar o "amor sofrido" tenta entregar-se ao texto da cidade, em cumplicidade com o seu lado vivo: o popular, as estórias, e a leitura irreverente dos textos e da própria cidade. Um momento desses, é quando trata como se fosse "um sítio à balda" um dos mais conhecidos e prestigiados locais de Lisboa, o Rossio.

A área é um marco central da cidade, com o Teatro Nacional D. Maria e com todo um arquivo de referências literárias e culturais que abriga: "uma praça de tertúlias das letras e da política", diz o escritor.

Apesar de sua importância, ou talvez por isso, Cardoso Pires retoma o que ele, em tom de piada, chama de enigma do Rossio. A estória é conhecida.

Segundo a versão debochada, a estátua de D. Pedro IV no alto do pedestal no centro do Rossio é, na verdade, de Maximiliano da Áustria, feita por um escultor francês para celebrar a coroação do arquiduque do império austrohúngaro como imperador do México. Na viagem que a levaria da Europa para o seu destino, o navio fez uma escala técnica em Portugal antes de cruzar o Atlântico. Nesse entretanto chega a notícia da revolução no México e do fuzilamento de Maximiliano pelos revoltosos. O comandante, precavido, desiste de seguir viagem e abandona a carga por ali mesmo, no porto de Lisboa. O governo português, pragmático, teria aproveitado a estátua como se fosse de D. Pedro, e a teria posto tão alto que o povo nem poderia dar pela troca.

O escritor, divertido com a estória, ri dos eruditos que torcem o nariz para ela, e se alinha com o "lisboeta corrente" que, segundo ele, não tem tempo a perder com isso e "até é capaz de achar graça". O escritor concorda e também acha que a estória continua a "animar a cidade", e que o Rossio não perde nada com o embuste e "ainda ganha um caso para entreter." 6

Esse é o tom do livro de bordo: o escritor, a despeito do amor sofrido, percorre a cidade em rota de navegação inteligente, às vezes apaixonada, às vezes bem humorada, e sempre reflexiva. Seu texto de viagem, longe de ser um manual para turistas, evita os roteiros previsíveis e os destinos seguros, tanto os da cidade quanto os da escrita.

${ }^{6}$ PIRES, José Cardoso. Lisboa Livro de bordo. Vozes, olhares, memorações. 4 ed., Lisboa: Dom Quixote. 1998. p. 15-16. 
Também o viajante do livro de Saramago vai, num momento da viagem, chegar a Lisboa. A entrada na cidade não é um momento pacífico também para ele, que se expressa da seguinte forma: "Enfim, para frente é que é Lisboa. Mas antes de cometer o feito, que no fundo da alma o está intimidando, o viajante irá a uma população ribeirinha chamada Carcavelos..."

Quando se refere à visita a Lisboa como um feito a cometer e quando admite estar intimidado, percebe-se o estranhamento que a cidade representa para o visitante, que diante da experiência do retorno parece desnorteado, sem bússola, sem roteiro prévio:

O viajante (...) é um viajante perdido. Aonde irá? Que lugares irá visitar? Que outros deixará de lado, por sua deliberação ou impossibilidade de ver tudo e falar de tudo? Tão legítimo seria atravessar o jardim e ir ver os barcos no rio como entrar no Mosteiro dos Jerónimos. (...) O viajante enche de bom ar o peito, como quem levanta as velas para apanhar o vento do largo, e ruma para os Jerónimos. ${ }^{8}$

A passagem sugere que para vencer a timidez inicial o viajante adia o contato com a cidade viva dos barcos no rio, mostrando-se ainda pouco a vontade com a experiência de se entregar ao mundo. Assim, opta por começar a visita por um local mais tranqüilizador para o intelectual que é, familiarizado com os arquivos da alta cultura.

Como por essa necessidade de refúgio, na seqüência do périplo pela cidade, o viajante de Saramago visita vários outros museus, como o de Antropologia, o de Arte Popular, e mais detidamente o solene e consagrado Museu de Arte Antiga, e o Museu Calouste Gulbenkian.

Se no livro de Cardoso Pires há uma predominância de referências literárias, no de Saramago as artes plásticas são especialmente prestigiadas, sobretudo nos museus e os monumentos. O narrador chega a notar isso e se justifica: "O viajante gosta de museus, por nada deste mundo votaria sua extinção em nome de critérios porventura modernos..." 9

\footnotetext{
${ }^{7}$ SARAMAgO, José. Viagem a Portugal. São Paulo: Companhia das Letras, 1990. p. 188.

${ }^{8}$ Id. Ibid. p. 190.

9 SARAMAGO, José. Op. Cit.
} 
Esse gosto pelos museus sugere o perfil do intelectual e sua formação culta. E é assim, carregando esse arquivo pessoal do homem letrado, que o viajante de Saramago chega à Baixa pombalina e ao Rossio.

A cena da visita ao Rossio funciona como uma imagem de retorno que ajuda a compreender a relação desses escritores com a contingência da rua, e da cidade própria.

As estratégias variam: Cardoso Pires passeia com divertido interesse pelas anedotas que se incorporaram ao folclore popular do Rossio. Em Saramago, o tom é outro, quase grave. Para chegar ao Rossio, o viajante sobe "uma dessas ruas comerciais", observando o processo de desfiguração que, segundo ele, sofreu a Lisboa moderna e continua a sofrer a contemporânea. Lisboa é, para Saramago, uma cidade autofágica, que não gosta de ruínas, e o resultado é que, segundo ele, "quebrou-se uma ligação cultural entre a cidade e o povo dela." 10

Diferentemente de Cardoso Pires, o viajante de Saramago, circunspecto, não se interessa pelo Rossio. A única referência à praça central de Lisboa é o registro de quem esteve só de passagem:

Defende-se o Rossio melhor (da quebra referida acima). Lugar confluente e defluente, não se abre francamente à circulação, mas precisamente é isso que retém os passantes. O viajante compra um cravo nas florestas do lago e, virando as costas ao teatro a que se recusa o nome de Almeida Garrett, sobe e desce a Rua da Madalena para ir à Sé. No caminho assustou-se com a ciclópica estátua eqüestre de D. João I que está na Praça da Figueira, exemplo acabado de um equívoco plástico que só raramente soubemos resolver: há quase sempre cavalo a mais e homem a menos. ${ }^{11}$

A passagem é curiosa e provoca várias questões. Apesar de dizer que a praça retém os passantes, ele mesmo não se detém nela. E, se vira as costas ao teatro, fica necessariamente de frente para a estátua de D. Pedro IV (ou de Maximiliano do México), mas não a vê e ruma para a Sé. É curioso esse

\footnotetext{
${ }^{10}$ SARAMAgO, José. Viagem a Portugal. São Paulo: Companhia das Letras, 1990. p. 192.

${ }^{11}$ SARAMAGO, José. Op. Cit.
} 
seqüestro do Rossio e dos seus casos pitorescos no relato do viajante, porque ele é um observador bastante atento de praças e monumentos.

Tanto é assim que o seu itinerário pela Baixa Pombalina é o da ligação entre as três praças. No Terreiro do Paço, faz considerações várias sobre o espaço amplo, a arquitetura e o uso dos prédios históricos; ainda admira a praça "belíssima", e observa detidamente a estátua de D. José que a domina. $\mathrm{Na}$ Figueira vê e comenta como crítico de arte a grande estátua de D. João I, que para ele é um equívoco plástico. Entre o Terreiro do Paço e a Praça da Figueira, o viajante não pára no Rossio e silencia sobre o monumento do seu enigma.

Tanto em Saramago como em Cardoso Pires, temos modos diferentes de enfrentar a nova experiência também literária para esses escritores que por essa vez não fazem ficção sobre a cidade, e sim relato de experiência.

A experiência da cidade é o retorno forçado à tradição perdida, só resgatável por traços e vestígios, como pensa Piglia. E esse signo da perda é explicitado pelo viajante de Saramago. Na chegada, se sente perdido; a seguir, considera as perdas da cidade: "que foi que se perdeu? Que foi que se ganhou?"; mais a frente, chega a capitular: "Foi a Alfama, mas não sabe o que Alfama é".

Percorrendo praças, monumentos e museus, o viajante de Saramago expressa os dilemas do intelectual, diante dos acervos de cultura de que dispõe. Também Cardoso Pires sente a "geometria esquiva" e as "ondulações" da cidade. Nele a defesa contra a cisão vem pela cumplicidade com mais "genuíno" dela, como se viu no caso do Rossio, mas também com as vozes dos outros sobre ela, embora saiba que todas as vozes são igualmente "incertas e errantes".

O navegante de Cardoso Pires termina a viagem por Lisboa sentado no café diante do Tejo, de costas para a cidade "que o viu partir"; o viajante de Saramago termina sua viagem ao país sentado na areia da praia, considerando que a viagem não acabou:

Quando o viajante sentou na areia da praia e disse "Não há mais que ver", sabia que não era assim. O fim duma viagem é apenas o começo doutra. É preciso voltar aos passos que foram dados para os repetir, e para traçar caminhos novos ao lado deles. É preciso recomeçar a viagem. Sempre. O viajante volta já. ${ }^{12}$

${ }^{12}$ SARAMAGO, José. Viagem a Portugal. São Paulo: Companhia das Letras, 1990. p. 257. 
A última palavra do livro de Cardoso Pires é partir, a última frase do livro de Saramago é O viajante volta já. Partir, voltar; esses são os movimentos da deriva em que se encontra o intelectual, em trânsito permanente, e permanentemente localizado na margem de dois mundos, que são para eles de alguma forma familiares e estranhos.

Os dois livros são testemunhos disso. Ao mesmo tempo investigam os limites e as possibilidades da narrativa e da própria Literatura, o que vem bem a propósito nessa mudança de milênio, e de crise de paradigmas teóricos. Os escritores deixam o porto seguro da ficção para a aventura dos relatos de experiência subjetivada do retorno, com a impossibilidade do presente e com a herança do passado irrecuperável. Cardoso Pires fala a partir desse lugar errante e incerto de "vozes, olhares, memorações". Saramago formula a idéia de que os viajantes podem prolongar-se em "memória, em lembrança, em narrativa", mas percebe que é "impossível falar de tudo". Ambos, voltando à idéia de Adorno, ainda buscam um abrigo, mas não sem nostalgia, pois só há lugar disponível na escrita precária e frágil da memória que, por se saber irresgatável, é preciso reinventar.

\section{Referências bibliográficas:}

ADORNO, Th. W. Minima Moralia. Trad. Artur Morão. Lisboa: Edições 70, 2001.

PIGLIA, Ricardo. "Memoria y tradición". Anais do 2 Congresso da Abralic. Vol. 1. Belo Horizonte: UFMG, 1991.

PIRES, José Cardoso. Lisboa Livro de bordo. Vozes, olhares, memorações. 4 ed., Lisboa: Dom Quixote, 1998.

SARAMAGO, José. Viagem a Portugal. São Paulo: Companhia das Letras, 1990. 